\title{
ADSORÇÃO/DESSORÇÃO DO EXPLOSIVO TETRIL EM TURFA E EM ARGISSOLO VERMELHO AMARELO
}

Sandra Zago Falone e Eny Maria Vieira*

Instituto de Química de São Carlos, Universidade de São Paulo, CP 780, 13560-970 São Carlos - SP

Recebido em 7/4/03; aceito em 12/4/04; publicado na web em 27/8/04

\begin{abstract}
ADSORPTION/DESORPTION OF THE EXPLOSIVE TETRYL IN PEAT AND YELLOW-RED ARGISSOL. This paper presents the study of adsorption/desorption of the explosive tetryl (2,4,6-trinitrophenylmethyl-nitramine) in different matrices, such as in natura soil, roasted soil, humic acid of soil, in natura peat, roasted peat and humic acid of peat. The aim of the study is to evaluate the interaction capacity of those matrices with the explosive. The analytic technique used was HPLC (high performance liquid chromatography), with UV-detection at $230 \mathrm{~nm}$. The Freundlich isotherms were utilized for the mathematical treatment of the data. The results indicated that in natura soil and in natura peat (with organic substances) are excellent matrices for the retention of tetryl, adsorbing it and keeping it immovable, preventing it from contaminating the groundwater. The largest adsorption of the explosive ocurred in in natura soil, while the smallest desorption was observed in in natura peat. After the calcination of the matrices, the smallest adsorption was observed, indicating that the retention occurs in the organic substance.
\end{abstract}

Keywords: explosive; adsorption; desorption.

\section{INTRODUÇÃO}

Um dos sérios problemas ambientais que são causados pelas indústrias de armamentos é a presença de explosivos em locais onde as munições foram manufaturadas, estocadas, usadas ou ainda desmilitarizadas $^{1}$, sendo tais artefatos dispostos indevidamente no meio ambiente ${ }^{2}$.

A produção, estocagem e disposição de explosivos nas instalações militares iniciou-se antes da I Guerra Mundial, embora a grande maioria destas instalações tenha aumentado e intensificado suas atividades durante a II Guerra Mundial. Na Alemanha e nos EUA há um grande número de locais altamente contaminados por explosivos e munições em geral ${ }^{2}$. No Brasil, a maior quantidade de explosivos é produzida pelo exército. A fabricação ou importação desses compostos por particulares é permitida somente com a autorização do Ministério do Exército, mesmo assim o risco de contaminação existe, uma vez que o controle do uso desses artefatos ainda é incipiente.

A principal fonte de contaminação de superfícies aquáticas por nitro-compostos está associada principalmente aos processos industriais de fabricação de bombas e munições em geral. A descarga de rejeitos gerados durante a manufatura e o processamento, bem como o nível de contaminação causado por explosivos variam amplamente, dependendo da intensidade das operações de manufatura e da eficácia das tecnologias empregadas no tratamento dos resíduos ${ }^{3}$.

Devido aos altos índices de contaminação por explosivos nos solos, nas águas superficiais e subterrâneas e em locais próximos de indústrias manufatureiras, surgiram vários estudos relacionados com a determinação destes compostos nos solos e nas águas ${ }^{4-8}$.

Os explosivos são compostos orgânicos que contêm nitrogênio, que se oxidam formando pequenas moléculas gasosas $\left(\mathrm{N}_{2}, \mathrm{H}_{2} \mathrm{O} \text { e } \mathrm{CO}_{2}\right)^{3}$ e que sob ação de um choque térmico, elétrico ou mecânico se decompõem rápida e espontaneamente, com a evolução de uma grande quantidade de calor e de gases, a elevada temperatura e pressão ${ }^{9}$. Os explosivos de importância industrial ou militar são aqueles que possuem um baixo poder de explosão e um elevado conteúdo energético ${ }^{10}$.

*e-mail: eny@iqsc.usp.br
Neste estudo utilizou-se o explosivo 2,4,6-trinitrofenilmetilnitramina, chamado de tetril, procedente da Supelco Park-USA. É também conhecido como tetranitrometilanilina, tetralita ou pironita ${ }^{11}$. $\mathrm{O}$ tetril possui solubilidade em água de $80 \mathrm{mg} \mathrm{L}^{-1}$ a $25^{\circ} \mathrm{C}^{12,13}$, e velocidade de detonação de $7570 \mathrm{~m} \mathrm{~s}^{-111}$. Este explosivo é preparado industrialmente pela mistura de sulfonítrica com dimetilamina, pela nitração em várias etapas utilizando ácido sulfúrico e ácido nítrico ${ }^{14}$.

A Figura 1 apresenta a fórmula estrutural do tetril ${ }^{11}$.<smiles>CN(c1c([N+](=O)[O-])cc([N+](=O)[O-])cc1[N+](=O)[O-])[N+](=O)[O-]</smiles>

Figura 1: Fórmula estrutural do tetril (2,4,6-trinitrofenilmetil-nitramina)

O contato com o tetril pode causar dermatites, coceira, inflamação da córnea, espirros, fadiga, anemia, tosse, irritabilidade, mal estar, dor de cabeça, cansaço, insônia, náusea e vômitos ${ }^{15}$. O nível máximo de tetril no ar é de $1,5 \mathrm{mg} \mathrm{m}^{-3}$ por $8 \mathrm{~h}$ de exposição diária ${ }^{16}$. Sua dose letal $\left(\mathrm{DL}_{50}\right)$ oral em camundongos é de $5000 \mathrm{mg} \mathrm{kg}^{-13}$.

O destino dos explosivos nos solos é bastante complexo e é resultante de vários fatores, sendo um deles a interação com os constituintes das diferentes frações contidas nos solos: ácido húmico, ácido fúlvico, humina, argila, óxidos, etc sendo de maior interesse a interação com a matéria orgânica.

A matéria orgânica existente nos solos, sedimentos e turfas consiste de mistura de compostos em vários estágios de decomposição, que resultam da degradação biológica de resíduos de plantas, animais e da atividade sintética de microorganismos ${ }^{17,18}$, sendo considerada um dos materiais mais complexos existentes na natureza. Contem compostos que podem ser convenientemente agrupados em subs- 
tâncias não húmicas e substâncias húmicas (SHs). As substâncias não húmicas incluem aquelas com características químicas definidas, tais como carboidratos, proteínas, aminoácidos, gorduras e ácidos orgânicos de baixa massa molecular, substâncias que são facilmente degradadas e têm vida relativamente curta. As SHs não exibem características físicas e químicas definidas, possuem alta massa molecular e causam coloração escura nos solos e nas águas ${ }^{18-20}$. São subdivididas em ácido húmico $(\mathrm{AH})$, ácido fúlvico $(\mathrm{AF})$ e humina, sendo fracionadas por diferença de $\mathrm{pH}^{19}$. O AH é a fração solúvel em meio alcalino, o AF é a fração solúvel em meio ácido e em meio alcalino e a humina é a fração insolúvel nos dois meios ${ }^{21}$. Estruturalmente, as três frações húmicas são semelhantes, diferindo na massa molecular e na quantidade de grupos funcionais ${ }^{22}$.

As SHs desempenham um papel importante no ambiente, regulando quase todos os processos que ocorrem no solo, como abastecimento de elementos nutritivos pela mineralização, em particular a liberação de oxigênio, fósforo, enxofre e micronutrientes; estabilização do $\mathrm{pH}$ e disponibilidade de nutrientes ${ }^{23}$. Essas substâncias adsorvem moléculas orgânicas sintéticas como os pesticidas, afetando a biodegradabilidade dessas moléculas ${ }^{24,25}$, sendo que o mesmo processo ocorre com os explosivos.

A interação de substâncias orgânicas (explosivos, por exemplo) com o solo, pode ocorrer de diversas maneiras, como adsorção, partição ou fixação química (reações irreversíveis entre tais moléculas e o solo), sendo a adsorção a forma de interação mais comumente verificada e estudada ${ }^{26}$. A adsorção é a interação do explosivo com as frações presentes no solo. É um processo determinante para se entender o destino dos explosivos, pois está relacionado diretamente aos processos de transporte, adsorção e bioatividade destes no solo ${ }^{27,28}$.

O movimento de moléculas orgânicas no solo pode ocorrer por lixiviação, escoamento superficial e volatilização ${ }^{29}$. A adsorção é um dos fatores importantes para o monitoramento do impacto ambiental que o poluente pode causar, sendo que quanto maior for a sua adsorção comparada com a dessorção, menor será a sua lixiviação.

Para descrever o fenômeno adsortivo foram utilizadas as isotermas de adsorção, que descrevem a relação entre a quantidade adsorvida e a concentração da solução em contato com o adsorvente.

\section{Formas de isotermas de adsorção}

Isotermas de adsorção ou de dessorção são curvas obtidas a partir da quantidade de soluto adsorvido em função da concentração desse soluto na solução em equilíbrio. Giles e colaboradores ${ }^{30}$ dividiram as isotermas de adsorção em quatro principais classes, de acordo com sua inclinação inicial e, cada classe, por sua vez, em vários subgrupos, baseados na forma das partes superiores da curva. As quatro classes foram nomeadas de isotermas do tipo S ("Spherical"), L ("Langmuir"), H ("High affinity") e C ("Constant partition"), apresentadas na Figura 2.

\section{Isotermas do tipo $\mathbf{S}$}

Este tipo de isoterma tem inclinação linear e convexa em relação à abcissa. A adsorção inicial é baixa e aumenta à medida que o número de moléculas adsorvidas aumenta. Isto significa que houve uma associação entre moléculas adsortivas chamadas de adsorção cooperativa.

\section{Isotermas do tipo $\mathbf{L}$}

A forma L possui inclinação não linear e côncava em relação à abcissa. Nesse caso, há uma diminuição da disponibilidade dos sítios de adsorção quando a concentração da solução aumenta.
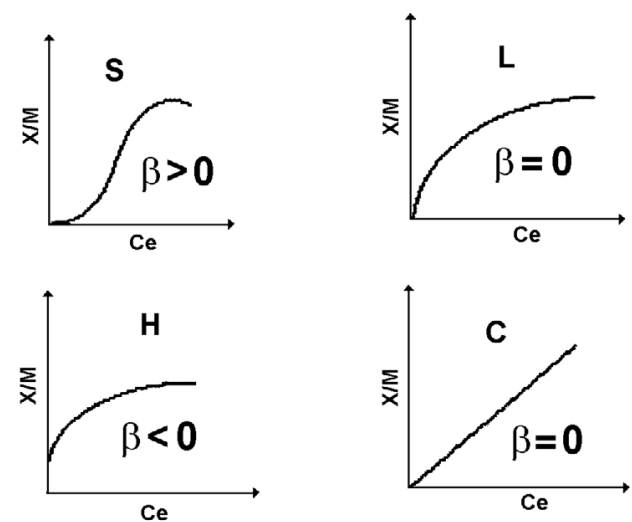

Figura 2. Classificação das isotermas de adsorção

\section{Isotermas do tipo $\mathbf{H}$}

Trata-se de um caso especial de curva do tipo L e é observada quando a superfície do adsorvente possui alta afinidade pelo soluto adsorvido.

\section{Isotermas do tipo $\mathbf{C}$}

Corresponde a uma partição constante do soluto entre a solução e o adsorvente, dando à curva um aspecto linear. As condições que favorecem as curvas do tipo C são substratos porosos flexíveis e regiões de diferentes graus de solubilidade para o soluto.

As isotermas do tipo $\mathrm{C}$ e L são freqüentemente muito próximas, podendo ser, em muitos casos, consideradas do mesmo tipo.

\section{Tratamento matemático das isotermas de adsorção}

Os testes de adsorção/dessorção baseiam-se na determinação das isotermas de adsorção de Freundlich do explosivo estudado. As isotermas de Freundlich obedecem a Equação 1:

$\log x / m=\log K f+1 / n \log C e$

em que: $\mathrm{x}=$ quantidade da substância adsorvida pelo solo $(\mu \mathrm{g}) ; \mathrm{m}=$ massa do solo (g); $\mathrm{Kf}=$ coeficiente de sorção (quantidade do explosivo adsorvido pelo solo para $\left.\mathrm{C}_{\mathrm{e}}=1 \mu \mathrm{g} \mathrm{mL} \mathrm{m}^{-1}\right) ; 1 / \mathrm{n}=$ fator de linearidade da isoterma; $c_{e}=$ concentração do explosivo na solução final em equilíbrio com o solo $\left(\mu \mathrm{g} \mathrm{mL}^{-1}\right)^{31}$.

Kf e $1 / n$ são parâmetros de regressão característicos para cada sistema solo-explosivo estudado. Quando o parâmetro $1 / n$ for igual a um, as isotermas tornam-se lineares. São do tipo L quando $1 / \mathrm{n}<1$ e do tipo $S$ para $1 / n>1$.

Quanto maior o valor de Kf, maior a capacidade de adsorção da substância pelo solo ${ }^{32}$.

Os valores de Kf são classificados de acordo com a Tabela 1.

Tabela 1. Classificação da adsorção (Kf), adaptada da ref. 32

\begin{tabular}{ll}
\hline Valor de Kf & Adsorção \\
\hline $0-24$ & Pequena adsorção \\
$25-49$ & Média adsorção \\
$50-149$ & Grande adsorção \\
$150-$ & Elevada adsorção \\
\hline
\end{tabular}

No presente trabalho, estudou-se a interação do explosivo tetril em Argissolo Vermelho Amarelo e na Turfa, na ausência e na presen- 
ça de matéria orgânica e nos seus respectivos ácidos húmicos, verificando-se o desempenho desses materiais quanto à adsorção/dessorção do explosivo.

\section{PARTE EXPERIMENTAL}

\section{Reagentes e solventes utilizados}

Todos os reagentes utilizados nos experimentos foram de grau analítico: Metanol (Tedia, 99,97\%), ácido clorídrico (Synth, 38\%), ácido nítrico (Synth, 65\%) e as soluções preparadas com água livre de orgânicos (sistema Milli-Q, Millipore). O padrão de referência de tetril foi obtido da Supelco (USA). As soluções de diferentes concentrações foram preparadas pela diluição do padrão do explosivo em solução de $\mathrm{CaCl}_{2} 0,01 \mathrm{~mol} \mathrm{~L}^{-1}$, para manter a força iônica próxima àquela da solução do solo.

\section{Coleta e preparo das amostras}

O solo utilizado nos estudos de adsorção/dessorção foi coletado na fazenda Canchim, situada no município de São Carlos-SP, em solos não cultivados e à profundidade de $10 \mathrm{a} 15 \mathrm{~cm}$. As amostras foram armazenadas em sacos de polietileno, secas ao ar, desagregadas em almofariz e peneiradas em malha $2 \mathrm{~mm}$.

As amostras de turfa utilizadas neste trabalho foram coletadas em uma turfeira localizada às margens do Rio Mogi-Guaçu, no km 40 da rodovia SP-255, no município de Luiz Antônio-SP. Foram coletadas a uma profundidade de 10 a $15 \mathrm{~cm}$, armazenadas em sacos de polietileno e conduzidas ao laboratório onde foram secas ao ar, desagregadas em almofariz e peneiradas em malha $2 \mathrm{~mm}$.

Para as amostras calcinadas (sem matéria orgânica), colocou-se 1,0 g de cada amostra in natura em cadinho de platina, e levou-se, posteriormente, para a mufla, onde foi mantida a uma temperatura de $600{ }^{\circ} \mathrm{C}$ durante $4 \mathrm{~h}$.

\section{Ácido húmico}

As extrações dos ácidos húmicos foram efetuadas conforme método adotado pelo "International Humic Substances Society (IHSS)" "33, que consiste na extração com base e separação com ácido com posterior purificação.

\section{Adsorção e dessorção do explosivo nas matrizes solo e turfa na presença de matéria orgânica e nas matrizes turfa e solo calcinados}

As isotermas de adsorção foram obtidas colocando-se $1,00 \mathrm{~g}$ de cada matriz em erlenmeyers de $150 \mathrm{~mL}$ e adicionando-se $10,0 \mathrm{~mL}$ de solução de $\mathrm{CaCl}_{2} 0,01 \mathrm{~mol} \mathrm{~L}^{-1}$ do explosivo tetril nas seguintes concentrações: 1,$0 ; 4,0 ; 7,0$ e $10,0 \mu \mathrm{g} \mathrm{mL}^{-1}$. As amostras foram submetidas a agitação orbital por $12 \mathrm{~h}$, à temperatura ambiente e no $\mathrm{pH}$ natural da matriz. Em seguida, as amostras foram centrifugadas por $20 \mathrm{~min}$ a $17.741 \mathrm{~g}$. Os sobrenadantes foram retirados cuidadosamente e analisados por CLAE.

Para a dessorção do explosivo, adicionaram-se outros 10,0 mL de $\mathrm{CaCl}_{2}$ 0,01 mol L-1 aos frascos onde se retirou o sobrenadante, agitou-se outra vez por $12 \mathrm{~h}$ em mesa agitadora orbital. Após esse tempo, repetiu-se o procedimento anterior ${ }^{19}$.

\section{Adsorção e dessorção do explosivo nas matrizes ácidos húmicos do solo e da turfa}

As isotermas de adsorção foram obtidas colocando-se $0,10 \mathrm{~g}$ de cada matriz em erlenmeyers de $150 \mathrm{~mL}$ e adicionando-se $10,0 \mathrm{~mL}$ de solução de $\mathrm{CaCl}_{2} 0,01 \mathrm{~mol} \mathrm{~L}^{-1}$, do explosivo tetril nas seguintes concentrações: 1,$0 ; 4,0 ; 7,0$ e 10,0 $\mu \mathrm{g} \mathrm{mL} \mathrm{mL}^{-1}$. As amostras foram submetidas a agitação orbital por $12 \mathrm{~h}$, à temperatura ambiente e no $\mathrm{pH}$ natural da matriz. Em seguida, as amostras foram centrifugadas por 20 minutos a $17.741 \mathrm{~g}$. Os sobrenadantes foram retirados cuidadosamente e analisados por CLAE.

Para a dessorção do explosivo, adicionaram-se outros $10,0 \mathrm{~mL}$ de $\mathrm{CaCl}_{2}$ 0,01 mol L-1 aos frascos onde se retirou o sobrenadante, agitou-se novamente por $12 \mathrm{~h}$ em mesa agitadora orbital. Após esse tempo, repetiu-se o procedimento descrito anteriormente ${ }^{19}$.

\section{Condições cromatográficas}

Para a determinação da concentração do tetril na solução em equilíbrio, utilizou-se um cromatógrafo em fase líquida (CLAE) Shimadzu com detector UV-Visível monitorado a $230 \mathrm{~nm}$, coluna RP-18 (15 cm x 4,6 mm x $5 \mu \mathrm{m}$ ), fluxo de 1,5 mL min ${ }^{-1}$, eluição com metanol/água (v/v) (50:50) e volume de injeção de $20 \mu \mathrm{L}$. Esses parâmetros foram os mesmos descritos por Bhadra et al..$^{34}$. O método foi validado de acordo com os parâmetros descritos por Amarante Jr. et al. ${ }^{35}$.

\section{Validação do método}

Pela equação da reta, estimou-se a sensibilidade, definida como $\mathrm{dy} / \mathrm{dx}$, que é a capacidade do método de distinguir com determinado nível de confiança duas concentrações próximas. Para o explosivo tetril obteve-se uma sensibilidade de 64,455 (unidades de área x L x $\left.\mathrm{mg}^{-1}\right)$.

Foram feitos estudos de recuperação para avaliar a exatidão do método. Tais estudos consistiram na fortificação das amostras, com quantidades conhecidas do explosivo, em diferentes níveis, seguida da determinação da concentração do composto adicionado. Foram encontradas, para este método, recuperações entre 91 e $115 \%$, sendo que para análises em nível de traços, porcentagens de recuperações entre 70 e $120 \%$ são necessárias para considerar o método exato. O método apresentou precisão satisfatória; analisou-se as amostras fortificadas em triplicata e os resultados obtidos foram bem próximos entre si, os coeficientes de variação foram inferiores a $10 \%$.

O limite de detecção de um método é definido pelo Comitê de Métodos Analíticos como a menor concentração que pode ser distinguida, com razoável confiança, da região de resposta do bran$\mathrm{co}^{35}$. Neste trabalho fez-se a estimativa do limite de detecção a partir dos experimentos de recuperação, utilizando o menor nível de fortificação. Foram encontrados os seguintes limites de detecção: $0,01 \mu \mathrm{g} \mathrm{g}^{-1}$ para o solo in natura, AH do solo e AH da turfa e para a turfa in natura, $0,03 \mu \mathrm{g} \mathrm{g}^{-1}$.

O limite de quantificação é definido como o menor nível de fortificação estudado, no qual a recuperação está entre 80 e $120 \%$ e com coeficiente de variação menor que $20 \%$. Para o explosivo estudado, o limite de quantificação foi de $1,0 \mu \mathrm{g} \mathrm{g} \mathrm{g}^{-1}$.

\section{RESULTADOS E DISCUSSÃO}

\section{Adsorção/dessorção do explosivo tetril}

As Figuras de 3 a 8 apresentam o tratamento dado às informações de adsorção e dessorção do explosivo em diferentes matrizes, na sua forma linearizada, estudados pelas isotermas de Freundlich. Os procedimentos descritos para isotermas foram empregados, apesar da temperatura não ter sido rigorosamente controlada. Os experimentos foram realizados à temperatura ambiente $\left(25\right.$ a $\left.27^{\circ} \mathrm{C}\right)$, intervalo esse que não sofreu grandes variações. 
A Figura 3 apresenta as isotermas de adsorção e de dessorção do tetril no solo in natura.

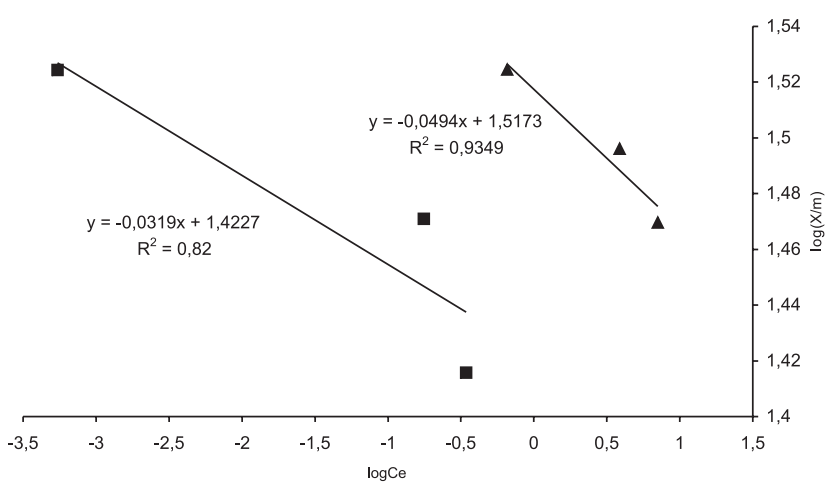

Figura 3. Isotermas de adsorção (\) e dessorção (ロ) do tetril no solo in natura

Estas isotermas apresentam um coeficiente de adsorção de 32,90 e de dessorção de 26,47. Este sistema apresenta a adsorção e a dessorção médias de acordo com os valores sugeridos por Lanças et $a l .{ }^{31}$ e IBAMA ${ }^{32}$. Entretanto, esta matriz contém constituintes que podem interagir fortemente com o tetril e possivelmente este composto estando adsorvido, não será lixiviado, nem biodegradado, uma vez que o mesmo estando livre no ambiente, degrada-se rapidamente, produzindo N-metil-2,4,6-trinitroanilina e, em menor quantidade, os isômeros dinitrofenilmetilnitramina, que são compostos mutagênicos, conforme foi observado por Harvey et $a l .{ }^{36}$.

A Figura 4 apresenta as isotermas de adsorção e de dessorção do tetril no solo calcinado.

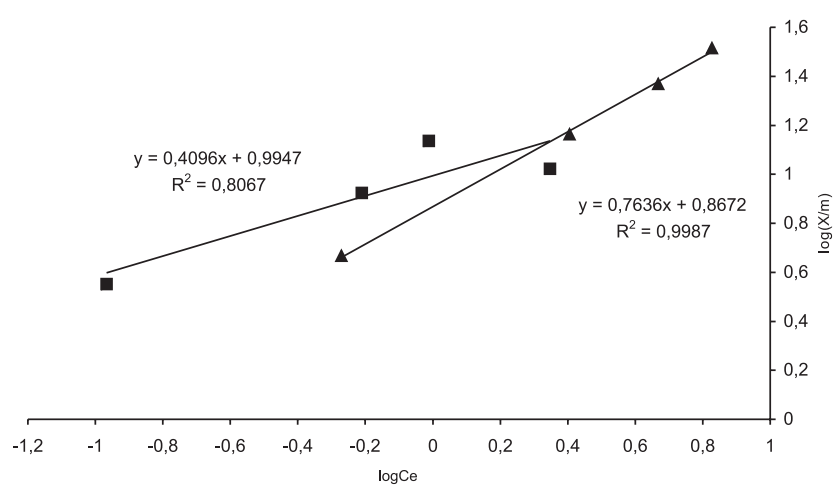

Figura 4. Isotermas de adsorção (山) e dessorção (অ) do tetril no solo calcinado

Estas isotermas apresentam o valor do coeficiente de adsorção de 7,37 devido, provavelmente, à interação do explosivo com as argilas, que foram ativadas durante a calcinação, tornando-as mais reativas, sendo que para as argilas não calcinadas, a adsorção apresenta valores muito baixos. Dessa baixa quantidade adsorvida, pouco se dessorveu, pois o valor do coeficiente da dessorção é 9,88 , sugerindo que maior quantidade ficou retida no solo calcinado do que livre na solução.

A Figura 5 apresenta as isotermas de adsorção e de dessorção do tetril no ácido húmico do solo.

Observou-se, para a adsorção do tetril no ácido húmico, um coeficiente de adsorção de 4,71 e de dessorção de 0,90. Esses valores sugerem que o tetril é pouco adsorvido pelo $\mathrm{AH}$, por isso possui maior tendência em ser lixiviado e biodegradado, contaminando as águas subterrâneas e superficiais, sendo mais adsorvido pelas fra-

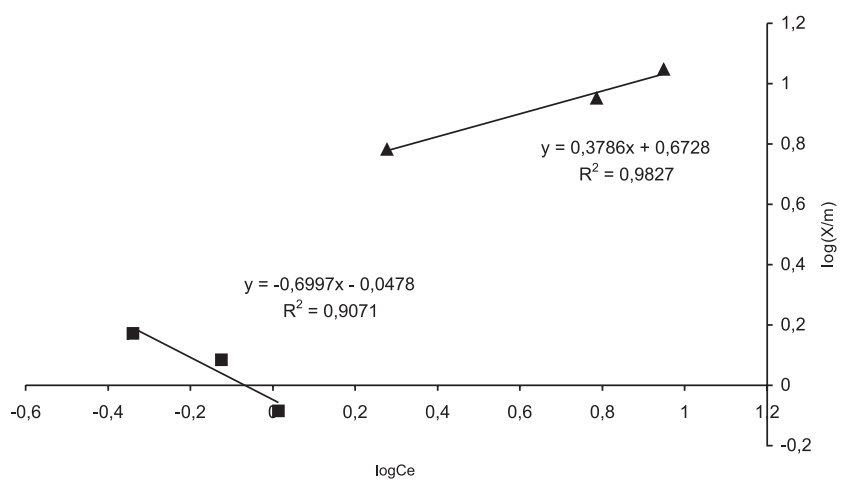

Figura 5. Isotermas de adsorção (山) e dessorção (ロ) do tetril no ácido húmico do solo

ções eliminadas da matriz in natura durante a extração do ácido húmico.

A Figura 6 apresenta as isotermas de adsorção e de dessorção do tetril na turfa in natura.

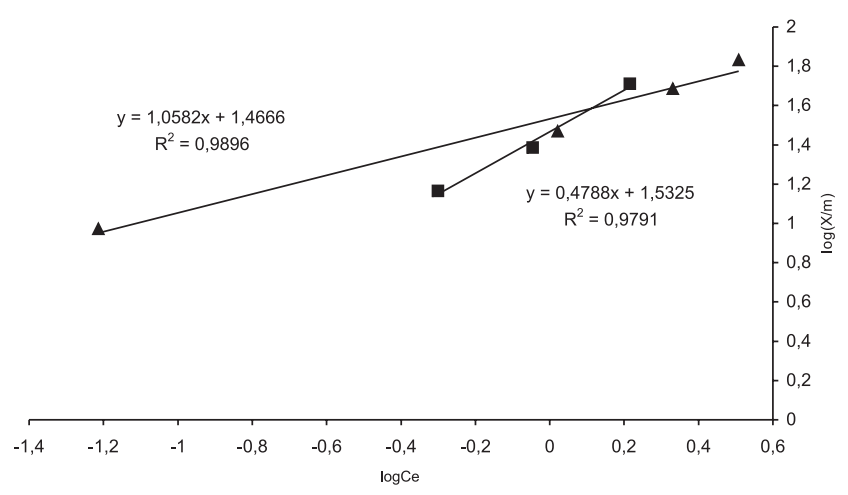

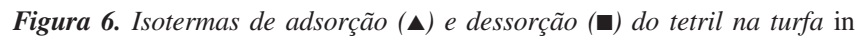
natura

O valor encontrado para o coeficiente de adsorção no estudo da interação do tetril com a turfa é de 29,28 e a dessorção, de 34,08. De acordo com Lanças et al. ${ }^{31}$ e IBAMA ${ }^{32}$, estes valores sugerem que toda a quantidade do explosivo que foi adsorvida, ficou retida na matriz. Esse comportamento deve ter ocorrido, provavelmente, devido a interações entre as substâncias húmicas presentes no ácido fúlvico e na humina com o explosivo estudado.

A Figura 7 apresenta as isotermas de adsorção e de dessorção do tetril na turfa calcinada.

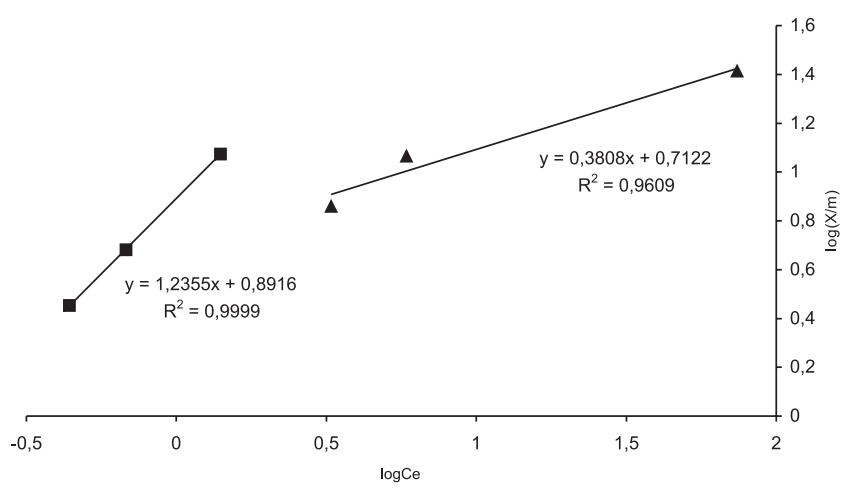

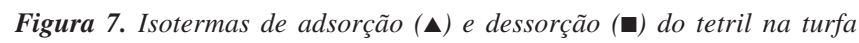
calcinada 
Estas isotermas apresentam efeitos semelhantes aos estudos realizados entre o tetril e o solo calcinado, sendo que da quantidade que foi adsorvida, um pouco dessorveu, e mesmo assim, a molécula do explosivo ficou mais retida na matriz do que livre na solução. Estas isotermas apresentaram um coeficiente para a adsorção de 7,79 e de dessorção de 5,15 .

A Figura 8 apresenta as isotermas de adsorção e de dessorção do tetril no ácido húmico da turfa.

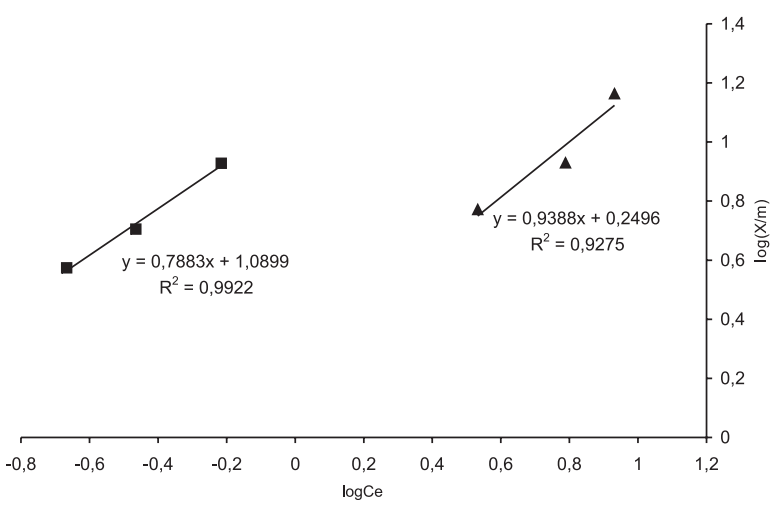

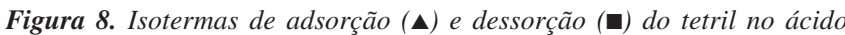
húmico da turfa

Pelos dados obtidos, pode-se dizer que o tetril é mais adsorvido na turfa calcinada que no $\mathrm{AH}$ da mesma, pelo baixo valor do coeficiente para a adsorção observado nesse sistema, que foi de 1,78. Esse valor mostra que uma pequena quantidade do explosivo foi adsorvida, entretanto nada se dessorveu, como se pode observar pelo valor do coeficiente para a dessorção que foi de 12,30 . O Kf de dessorção dessa matriz foi maior que na turfa calcinada. Isto sugere que o explosivo ao ser adsorvido na superfície do $\mathrm{AH}$ provavelmente não será lixiviado para camadas inferiores, ou seja, haverá uma diminuição de sua mobilidade no meio ambiente.

As Figuras 3 a 8 apresentam as constantes de Freundlich para as diferentes matrizes (solo, solo calcinado, AH do solo, turfa, turfa calcinada e AH da turfa), as quais estão dispostas na Tabela 2.

Tabela 2. Constantes de Freundlich a partir dos gráficos do tetril para as diferentes matrizes.

Tetril

\begin{tabular}{lrrrr}
\hline Amostras & \multicolumn{2}{c}{ Adsorção } & \multicolumn{2}{c}{ Dessorção } \\
& \multicolumn{1}{c}{$\mathrm{Kf}_{\mathrm{a}}$} & $1 / \mathrm{n}$ & \multicolumn{1}{c}{$\mathrm{Kf}_{\mathrm{d}}$} & $1 / \mathrm{n}$ \\
\hline Solo & 32,91 & 0,05 & 26,47 & 0,03 \\
Solo calcinado & 7,37 & 0,76 & 9,88 & 0,41 \\
AH do solo & 4,71 & 0,34 & 0,90 & $-0,70$ \\
Turfa & 29,28 & 1,06 & 34,08 & 0,48 \\
Turfa calcinada & 7,79 & 1,23 & 5,15 & 0,38 \\
AH da turfa & 1,78 & 0,94 & 12,30 & 0,79 \\
\hline
\end{tabular}

$\mathrm{O}$ valor de $1 / \mathrm{n}$ para a adsorção do tetril na turfa e no $\mathrm{AH}$ da turfa são próximos de um, com isso apresenta curvas quase lineares. $\mathrm{O}$ valor de $1 / n$ na turfa calcinada no processo de adsorção apresenta isotermas do tipo S, que se caracterizam pela baixa adsorção inicial, aumentando à medida que ocorre o aumento do número de moléculas adsorvidas. As demais isotermas, tanto para o processo de adsorção, quanto para o de dessorção apresentam os valores de $1 / n$ como isotermas do tipo L. Este tipo de comportamento ocorre quando há uma diminuição da disponibilidade dos sítios de adsorção, em decorrência do aumento da concentração do explosivo na solução.
Os valores de Kf do tetril mostram uma maior adsorção na turfa e no solo in natura, provavelmente devido a interação do explosivo com outros componentes dessas matrizes, como é apresentado na Figura 9.

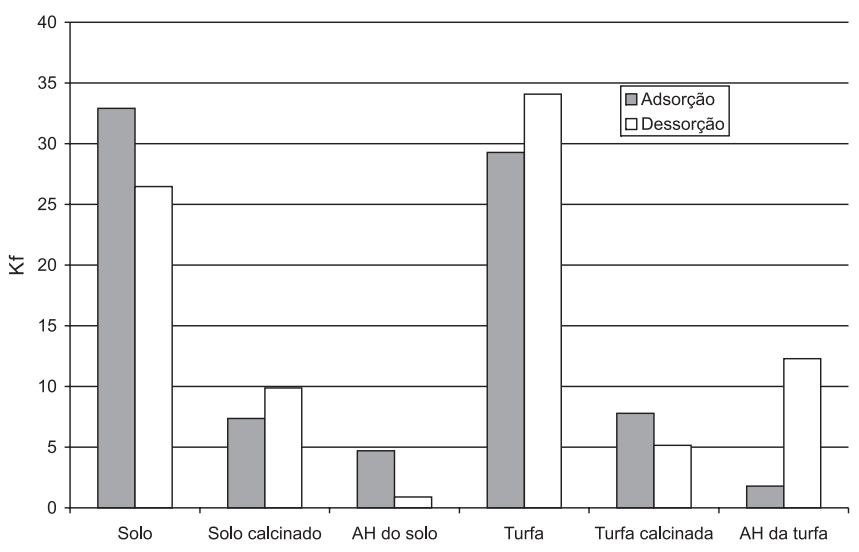

Figura 9. Comparação entre a quantidade adsorvida e dessorvida do explosivo

Considerando o tratamento matemático utilizado para avaliar o processo de adsorção, pode-se observar que os valores dos coeficientes de dessorção presentes nas amostras de solo e turfa in natura são altos, o que representa uma baixa dessorção do explosivo nessas matrizes.

\section{CONCLUSÕES}

Analisando-se os valores de Kf, pode-se concluir que o explosivo tetril apresentou maior adsorção e menor dessorção nas matrizes in natura que nos ácidos húmicos das mesmas, interagindo mais com o ácido fúlvico, humina, substâncias não húmicas e componentes inorgânicos que propriamente com os ácidos húmicos.

\section{AGRADECIMENTOS}

\section{À CAPES e à FAPESP.}

\section{REFERÊNCIAS}

1. Jenkins, T. F.; Walsh, M. E.; Talanta 1992, 39, 419.

2. Darrach, M. R.; Chutjian, A.; Plett, G.; Environ. Sci. Technol. 1998, 32, 1354.

3. Rodgers, J. D.; Bunce, N. J.; Water Res. 2001, 35, 2101.

4. Kleiböhmer, W.; Cammann, K.; Mussenbrock, E.; J. Chromatogr. 1993, $638,349$.

5. Steuckart, C.; Berger-preiss, E.; Levsen, K.; Anal. Chem. 1994, 66, 2570.

6. Caton, J. E.; Griest. W. H.; J. Liq. Chromatogr. Relat. Technol. 1996, 19, 661.

7. Vieira, E. M.; Onuska, F. I.; Water Qual. Res. J. Can. 1999, 34, 533.

8. Onuska, F. I.; El-shaarawi, A. H.; Terry, K.; Vieira, E. M.; J. Microcolumn Sep. 2001, 13, 54

9. Zarzuela, J. L.; Aragão, R. F.; Química Legal e Incêndios, SagraLuzzatto: Porto Alegre, 1999.

10. http://www.primeperforating.com/CATALOGU/SEARCH/index.htm, acessada em Julho 2001.

11. Meyer, R.; Explosives, Verlag Chemie: Weinheim, 1981.

12. Weast, R. C.; Crc Handbook of Chemistry and Physics, CRC Press: Boca Raton, 1988

13. Hutzinger, O.; The Handbook of Environmental Chemistry: Antropogenic Compounds, Springer-Verlag: Berlin, 1991.

14. Shereve, R. N.; Indústrias de Processos Químicos, Guanabara Dois: Rio de Janeiro, 1980.

15. http://www.crystalizedcarbon.com/fortweb/tetrylATSDR.htm, acessada em Outubro 2001

16. The Merck Index, 12.ed., Merck: Whitehouse Station, 1996. 
17. Jordão, C. P.; Costa, E. D.; Brune, W.; Goulart, A. T.; Quim. Nova 1993, 16, 517.

18. Silva, W. T. L.; Vieira. E. M.; Rezende. M. O. O. R.; Quim. Nova 1995, $18,541$.

19. Tavares, M. C. H.; Landgraf, M. D.; Vieira, E. M.; Rezende, M. O. O.; Quim. Nova 1996, 19, 605

20. Prado, A. G. S.; Rezende, M. O. O.; An. Assoc. Bras. Quím. 1999, 48, 186.

21. Landgraf, M. D.; Silva, S. C.; Rezende, M. O. O.; Anal. Chim. Acta 1998, $368,155$.

22. Fukushima, M.; Tanaka, S.; Nakamura, H.; ITO, S.; Talanta 1996, 43, 383.

23. Lindsay, W. R.; Chemical equilibria in soil, Elsevier: New York, 1972.

24. Kiehl, E. J.; Fertilizantes orgânicos, Agronômica Ceres: São Paulo, 1985.

25. Barros, M. C. P.; Paula, J. R.; Rezende, M. O. O.; Quim. Nova 1994, 17, 376.

26. Falone, S. Z.; Dissertação de Mestrado, Universidade de São Paulo, Brasil, 2002.

27. Vieira, E. M.; Prado, A. G. S.; Landgraf, M. D.; Rezende, M. O. O; Quim. Nova 1999, 22, 305.

28. Selim, H. M.; Xue, S. K.; Iskandar, I. K.; Soil Sci. 1995, 160, 328.
29. http://www.crystalizedcarbon.com/fortweb/RdxATSDR.htm, acessada em Outubro 2001

30. Giles, C. H.; Macewan, T. H.; Nakhwa, S. N.; Smith, D.; J. Chem. Soc. 1960, 3973

31. Lanças, F. M.; Vilegas, J. H. Y.; Galhiane, M. S.; Pest. Ver. Téc. Cient. 1994, 4,39 .

32. IBAMA; Manual de testes para a avaliação da ecotoxicidade de agentes químicos: E-2 - Teste para Avaliação da Mobilidade, Brasília, 1990.

33. Rosa, A. H; Rocha, J. C.; Furlam, M.; Quim. Nova 2000, 23, 472.

34. Bhadra, R.; Wayment. D. G.; Williams, R. K.; Barman, S. N.; Stone, M. B.; Hughes, J. B.; Shanks, J. V.; Chemosphere 2001, 44, 1259.

35. Amarante Jr., O. P.; Caldas, E. P. A.; Brito, N. M.; Santos, T. C. R. S.; Vale, M. L. B. F.; Caderno Pesq. 2001, 12, 116.

36. Harvey, S. D.; Fellows, R. J.; Campbell, J. A. Cataldo, D. A.; J. Chromatogr. 1992, 605, 227 